\section{$\underset{\substack{\text { hommes } \\ \text { \& migrations }}}{ }$}

\section{Hommes \& migrations}

Revue française de référence sur les dynamiques

migratoires

1335 | 2021

Saisir le murmure du monde

\title{
Exhumer les traces sensibles de l'immigration
}

\section{Marie Poinsot}

\section{(2) OpenEdition \\ Journals}

\section{Édition électronique}

URL : https://journals.openedition.org/hommesmigrations/13238

DOI : 10.4000/hommesmigrations. 13238

ISSN : 2262-3353

\section{Éditeur}

Musée national de l'histoire de l'immigration

\section{Édition imprimée}

Date de publication : 1 octobre 2021

Pagination : 1

ISBN : 978-2-919040-59-9

ISSN : $1142-852 X$

\section{Référence électronique}

Marie Poinsot, «Exhumer les traces sensibles de l'immigration », Hommes \& migrations [En ligne], 1335 | 2021, mis en ligne le 01 octobre 2021, consulté le 22 février 2022. URL : http:// journals.openedition.org/hommesmigrations/13238; DOI : https://doi.org/10.4000/ hommesmigrations. 13238 


\section{Édito}

\section{Exhumer les traces sensibles de l'immigration}

Marie Poinsot,

rédactrice en chef de la revue.

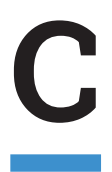

oordonné avec brio par un quatuor d'historiennes, ce numéro livre des questionnements prometteurs sur la démarche de l'histoire dite «par le bas». Au moment où la place des récits individuels est reconsidérée dans l'historiographie, la revue invite à se pencher sur la multitude des visages incarnés par les écritures de l'intime, même si ces derniers se cachent dans des fonds administratifs austères. Car l'entrée par les récits réfute la linéarité du temps long et l'appréhension globale des migrations. Elle reconstitue des itinéraires bousculés, valorise la capacité des migrants à agir sur leur destin et à se reconstruire symboliquement. Elle fait aussi ressurgir des lieux et des territoires privés des traces de leur passé «migratoire ». Ainsi découvre-t-on la complexité des situations d'exil, la diversité des vies fragmentées, l'ampleur des traumatismes et des violences passées sous silence. Les récits évoquent la manière dont les appartenances sociales, culturelles et genrées se transforment avec les migrations, tout en mobilisant des mémoires contre l'effacement du temps.

\section{Les formes cisèlent les récits}

La polyphonie "des manières de faire récit» - archives, cartographies, témoignages, photographies, films, fictions, correspondances, etc. - nous livre des regards multiples sur les migrations qui sont autant de versions de la vie de chacun et de ses aléas. La diversité des formes et des supports de l'énonciation imprime sa marque aux narrations de soi. Deux collections du Musée national de l'histoire de l'immigration ont été sélectionnées pour le portfolio. Elles proviennent de studios de quartier tenus par des photographes étrangers qui ont enregistré des moments de la société locale dans la France de l'entre-deux-guerres: récits visuels de la communauté polonaise dans les mines du Pas-de-Calais, saisis par Kasimir Zgorecki, et ceux de la communauté arménienne mis en scène par l'objectif de Krikor Djololian.

\section{Le 17 octobre 1961 pour mémoires}

La revue a souhaité commémorer les 60 ans du massacre du 17 octobre 1961 en privilégiant l'histoire des représentations militantes, littéraires, cinématographiques de cette tragique manifestation d'Algériens, venus protester à Paris contre le couvrefeu et pour la paix. Ces productions culturelles racontent les mémoires des manifestants contre la force de l'oubli. D'autres angles inédits évoquent le 17 octobre 1961, notamment une lecture britannique des travaux historiques qu'analyse Alec Hargreaves, l'observation outre-Atlantique des arts visuels qui relatent la manifestation et que propose Lia Brozgal, sans oublier la participation des Algériennes que racontent quatre planches BD réalisées pour la revue.

\section{Étrangers et artistes en récit}

Alors que le Musée inaugure cet automne une exposition sur Picasso, l'étranger, Annie Cohen-Solal en charge du commissariat, retrace la méthode et les étapes de la vaste enquête qu'elle a menée dans les archives pour reconstituer la trajectoire de cet artiste de génie. Elle considère le récit de son exil volontaire à Paris comme le point central de son inspiration créatrice et montre combien son statut précaire d'étranger a irrigué toute l'œuvre de Picasso. Un siècle après René Maran qui avait obtenu le prix Goncourt pour son roman Batouala (Albin Michel), c'est au tour de Mohamed Mbougar Sarr d'être couronné du même prix prestigieux pour La plus secrète mémoire des hommes (Philippe Rey/Jimsaan), un récit labyrinthique sur le parcours littéraire du mystérieux T. C. Elimane. La revue se réjouit du succès de ce jeune écrivain, déjà lauréat du Prix littéraire de la Porte Dorée en 2018. Ce roman inventif et fulgurant, en partie écrit lors d'une résidence d'écriture au Musée, rend hommage à la littérature qui, par l'écriture du récit, «relate» et «relie » autrement le temps de l'exil. 